\title{
Faszinierende Technik
}

\section{Liebe Leserin, lieber Leser,}

die Technik von Offroad-Nutzfahrzeugen ist faszinierend - stellt aber auch hohe Ansprüche an die Konstrukteure und Entwickler. Und diese Ansprüche werden laufend höher. Konnten Ingenieure früher teils noch erfahrensorientiert Produkte entwickeln, müssen sie heute das Gesamtsystem betrachten. So nutzt der Engineering-Dienstleister IAV beispielsweise einen systematischen Vorentwicklungsprozess, der die Gesamtkomplexität möglichst früh erfasst. Wie dieser Prozess aufgebaut ist, können Sie in unserem ersten Titelbeitrag ab S. 6 nachlesen.

Die Gesetzgebung ist neben Kundenanforderungen ein maßgeblicher Treiber für die steigende Komplexität. So mussten unter anderem durch die sich in den letzten Jahren ständig verschärfenden Abgasnormen immer neue Lösungen für den Motorraum gefunden werden. Das Resultat ist, dass immer mehr Komponenten im Motorraum - und wo dies nicht mehr gelingt außerhalb - untergebracht werden müssen, mit den damit verbundenen Problemen. Dies hat dann wiederum auf andere Komponenten Einfluss, beispielsweise bei Fahrmischern. Bei diesen Fahrzeugen wird unter anderem der Bauraum für den Trommelantrieb durch neue Abgasreinigungsanlagen immer begrenzter. Zusätzlich erhöht sich durch die neuen Abgasreinigungskomponenten stetig das Fahrzeuggewicht, das an anderer Stelle wieder eingespart werden muss, um den Kraftstoffbedarf nicht zu erhöhen. Die neueste Generation der ZF-Mischergetriebe erfüllt diese und weitere Anforderungen. Wie dies realisiert wurde, beschreibt der zweite Titelbeitrag ab S. 18.

Die kommende Abgasnorm EU Stufe V wird diese Problematik nochmals verschärfen. Diese Abgasnorm ist sehr ähnlich wie die Euro VI und bedingt, dass durch die Begrenzung der absoluten
Zahl an Partikeln noch ein Partikelfilter in den schon überfüllten Motorraum integriert werden muss. Wie führende Hersteller wie MAN Truck \& Bus mit diesen Herausforderungen umgehen, lesen Sie in unserem Interview mit Dr. Carsten Intra ab S. 14.

Wie eingangs erwähnt, sind Nutzfahrzeuge und deren Technik vor allem aber eins - faszinierend. Daher freue ich mich immer wieder auf die großen Fahrzeugmessen, um mir live die technischen Lösungen erklären zu lassen, aber natürlich auch, um Kontakte aufzufrischen beziehungsweise neue herzustellen. Ich hoffe daher, wir sehen uns auf der nächsten IAA Nutzfahrzeuge Ende September in Hannover.

Ihr

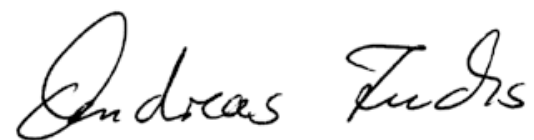

Andreas Fuchs

Chefkorrespondent

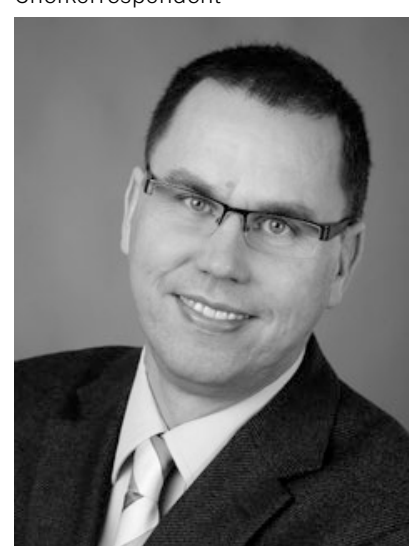

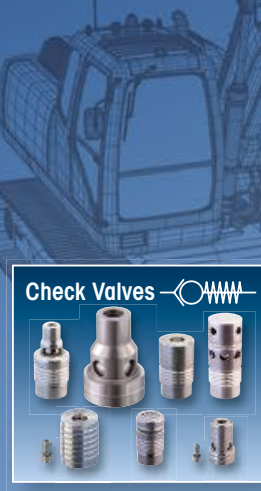

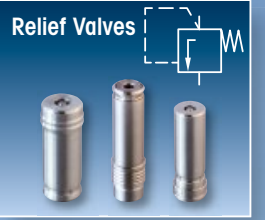

Flow Controls
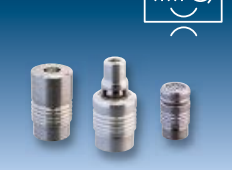

Restrictor Checks $\asymp \mathrm{O}$
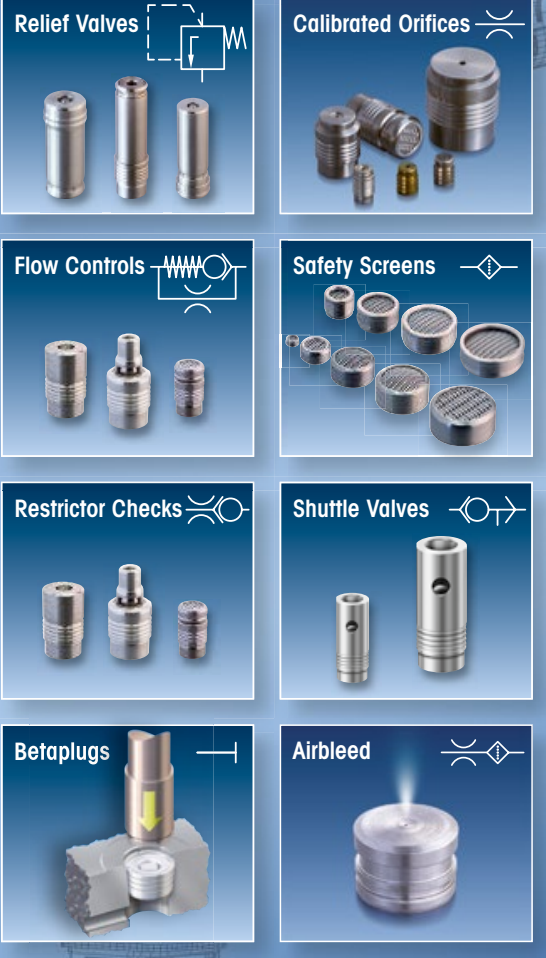



Innovation in Miniature 